\title{
Research on the Development Direction and Trend of Interior Design Education under the Green Building Background
}

\author{
Jianwei Ban \\ Hebei Academy of Fine Arts, \\ Shijiazhuang City of Hebei Province, 050700
}

\begin{abstract}
In this paper, we conduct research on the development direction and trend of interior design education under the green building background. Due to the development of the social economy and people living standard rise, the public has produced great changes to the requirement of the interior design, for interior designers professional ability is also put forward higher requirements. As the main position of interior design talent cultivation, universities of professional interior design must be according to these changes, corresponding education reform. Reform must be from the construction of curriculum system, teaching content and teaching method and so on as all aspects of interior design education to promote at the same time, in order to achieve their purpose. Our research proposes the novel paradigm for the interior design education which will enhance the current teaching mode.
\end{abstract}

Keywords- Green Building, Interior Design, Direction and Trend, Background, Education.

\section{Introduction}

With the accelerating urbanization and the deepening of the construction and the development in our country, the construction engineering construction and contradiction between resources, environment is being more and more acute. Green building design and the construction to a large extent eased the contradiction between architectural design and construction and environmental resources, but in the actual operation process, the green building design also has many problems, therefore, in the current green building engineering design and construction of how to implement ecological and the energy saving has become the current architectural construction needed to solve the problem [1-2].

At present people to the understanding of the basic meaning of green building that can be roughly divided into two categories, namely: the "target" and "process". "Target" is a kind of lateral thinking, the green building as an ideal target contains a lot of content, maybe not now, but we strive to practice. "Target" summarizes the basic principles of green architecture and constitutes the basic framework of green building. "Process" is dynamically defined green building development. Process for a particular building individual, "said" think green building is a with the whole life cycle of each phase continuous construction concept, for the development of construction project decision-making, planning, design, construction and operation maintenance respectively in each stage of the specific requirements are put forward. Under these two definitions, the characteristics of the green building could be organized as the following aspects. (1) Green building has the characteristics of environmental protection. In the process of the development of green building, it will not be able to causing the greater damage to the surrounding environment and interference. Through the scientific and reasonable design, with use of energy conservation and environmental protection material, adopt the latest construction technology, which takes the concept of environmental protection through to each link of the construction of the building to realize the environmentally friendly development of the construction projects. (2) Green building has the characteristics of energy saving. Compared with 
ordinary buildings, one of biggest features of the green building, can be reflected in terms of energy saving. In green building design and construction process, the related staff to take full use of renewable energy sources such as wind, solar, and biomass energy or natural energy and thus easing the shortage of resources in current situation. (3) Green building has characteristics of safe and comfortable. In green building design and construction process, it must be able to reflect the humanistic building standards. In the actual operation process, relevant staff to rational ventilating and lighting design as the green architecture design to be able to complies with relevant design standards, on basis of meet the characteristics of safe and comfortable, so as to realize the environmental protection of green building design and human nature.

The meaning of ecological aesthetics is very wide, from small, the ecological aesthetics is mainly aimed at people with the natural environment of the special ecological aesthetic relationship, and from a wide range, the research object of ecological aesthetics includes people, the overall ecological aesthetic relationship between society and nature, it is guided by the scientific ecological values and world view, man and society, man and nature and people's own development, such as the multiple aesthetic relations that is an exploration and harmonious new ecological ontological aesthetics. As the illustration, we show the sample green architecture in the figure one [3-4].

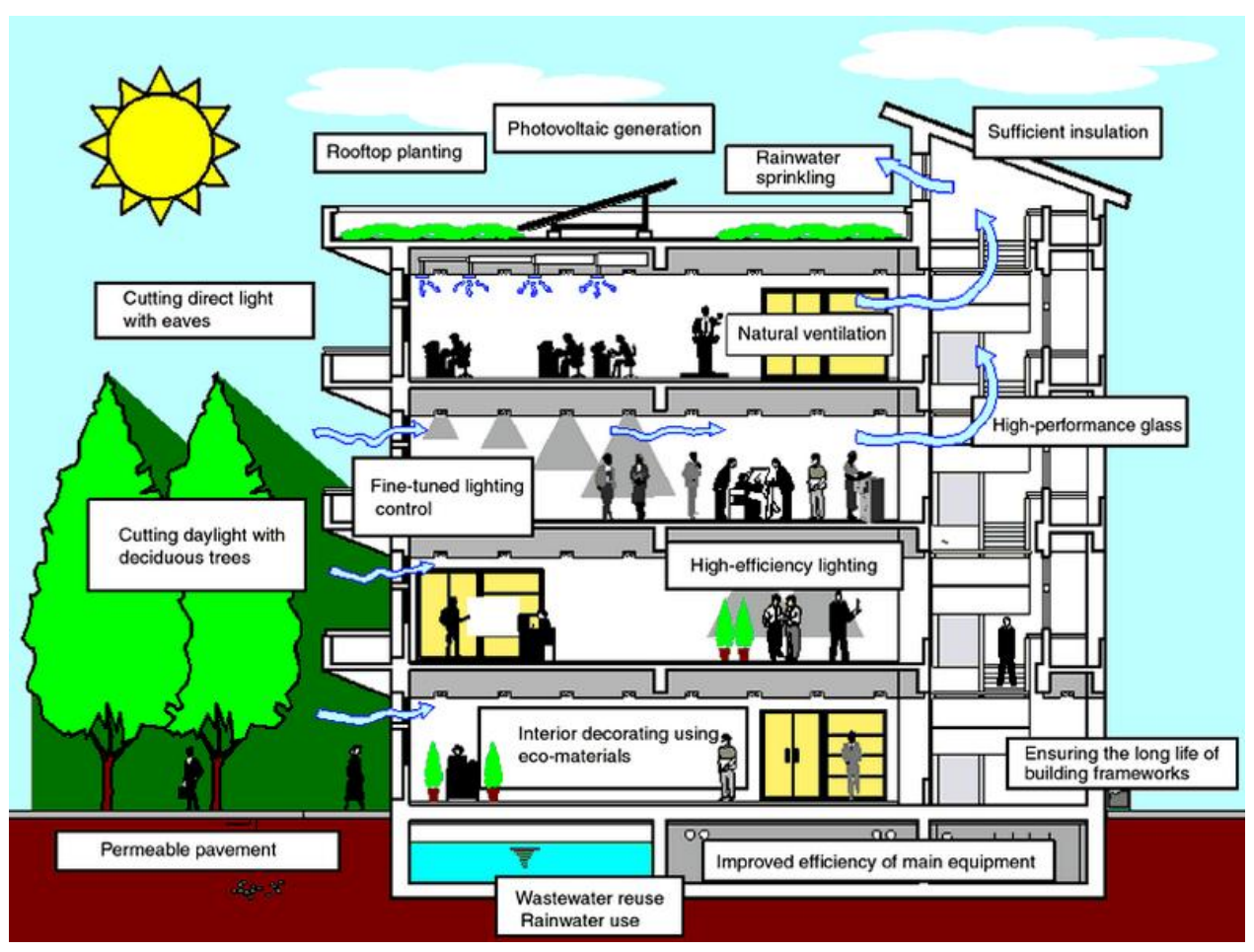

Figure 1. The Demonstrative Structure of the Green Building System

In this paper, we conduct research on development direction and trend of interior design education under the green building background. Based on the green architecture perspective, the rest of article will focus on listed aspects. (1) Effective use of renewable resources, avoid excessive consumption of non-renewable resources and waste. The modern interior design should as far as possible with use of renewable resources, and circulatory use of resources. (2) Concise form, avoid too trival adornment and materials piled up. The from all walks of life 
form, each node of interior design modelling, and furniture should as far as possible concise form, on the premise of meet the use function and aesthetic demand, avoid complex trival adornment element material increase and related bring pollution, visual pollution and the complex decoration. (3) Green house, the effective use of green plants to create a comfortable with indoor environment. Green plants which could create the microenvironment of the ecological health, but also can satisfy the desire of people to the natural, appropriate adorn greenery in the interior space is accord with the principle of the green interior design.

\section{The Proposed Methodology}

The Principles of Interior Design. It is the continuation of architectural design, interior design is the deepening of architectural conception is to create the environment, is an important part of the design intent. With the development of building science and human use function to ask for more detailed to the environment, interior design has become an independent design in architectural design phase, the academic has also become a new branch of architecture. Design is a design by human, which meet the needs of people physiology and psychology, the material and spiritual needs. Design is the main body of people, design the users and designers are human, so is the center of the design and size. This scale is including physical dimensions, and includes the psychological scale, and psychological dimensions meet is realized through the humanized design. In this sense, the emergence of humanized design and human design, completely is the essence of design requirements, it is by no means designers' chase the result. The features of modern interior design could be summarized as follows.

- Rich imagination. Design thinking is the starting designers in the design and the key, so no matter which kind of design creation, creative thinking is the premise of personalized design. Therefore, we can see that the importance of the creativity in design, the thinking process of the creativity from the known into the unknown, it will be our known reality through the basic sublimation and creation of art, to produce more new items is suitable for the environment and people's life. So as a modern designer to create a good design work, the designer itself must have a transcendental imagination [5].

- The innovation of the space division. A good interior design, in addition to need a good idea for the premise, and also need to spend on the details of the space division. In general, in order to make the design of indoor environment is more in line with the requirements of function, aesthetic, and adapt to the user's personality and cultural level, the designer must understand and master how to coordinate and deal with the space.

- The scientific analysis and choices in the process of creativity. Imagine the process finish does not mean that will inevitably produce good ideas or complete. Therefore, in the process of the idea that the use of imagination and analysis, through analysis that can be in a variety of the imagination results in choose the suitable way. There is no scientific analysis, the process of choosing, just also can't imagine, so it is easy to make creative deviates from the goal.

The Interior Design Education Paradigm. Interior design education development so far, its development speeds quickly. Decades of the education practice, this result is significant, not only to strengthen the basic design education, the training of specialists in the field of the interior design, and vigorously promoted our country education to develop in the general direction of modernization and internationalization of interior design. 

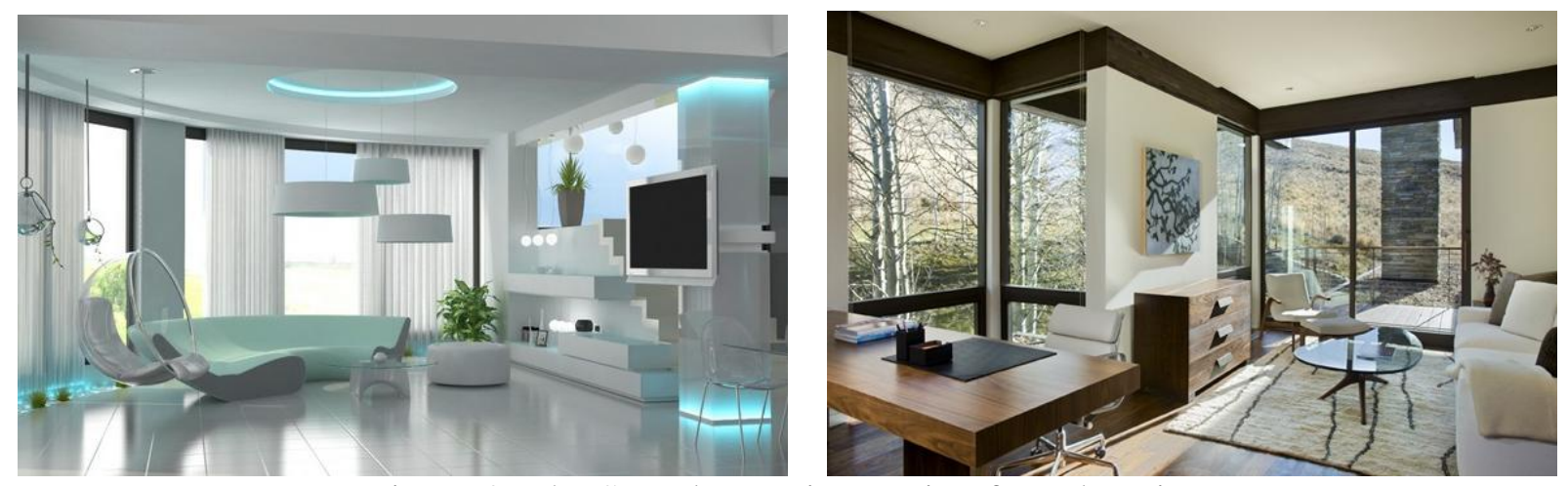

Figure 2. The Sample Interior Design for Education

As shown in the figure two, we show the sample interior design pattern for education. As the revise form of the curriculum structure, we should pay attention to the listed aspects. (1) Reinforcing the training of basic drawing, add landscape sketch course. Add landscape sketch lesson, as should with pure painting, building, construction should be emphasized performance from the sky and ground and other entourage of relationship. The choice of the construction can be varied in form, can be either a modern building, also can be a traditional dwellings, through sketch to understand diverse structures and a variety of decorative style. (2) Pay attention to professional knowledge training, strengthen the interior design creative consciousness. Interior design is in limited space to achieve integration of the function and aesthetic atmosphere and style, in order to meet the needs of the people's material and spiritual two big functions. To meet use function on the basis of how to create a beautiful environment, create high taste, will depend on the designer's professional knowledge accomplishment, depends on the designer the pursuit of creative consciousness. (3) Improve the teaching content. Interior design to design personnel according to nature of the building, a beautiful environment and the corresponding standards to create a comfortable, reasonable function and indoor environment which can fully satisfy people's needs in the process can well reflect the historical context, the environment atmosphere, etc. (4) Pay attention to classroom theory combined with social practice. The possibility of strengthening practice not only greatly improve the design of the bid, at the same time also can improve students' interior design scheme of fast performance, to help students learn to solve more practical problems. Teaching practice, through the electronic teaching, so that the students from the comprehension to the variety of architectural styles and construction process, etc.

The Education Reform Orientation. Any reform is to deal with the basic relationship between inheritance and innovation, adhering to the people-oriented thoughts, new curriculum to keep pace with The Times to put forward many new ideas, advocate a lot of new style, the content of the "new" is the highlight of the new curriculum, the characteristics, is to promote and lead the direction of the reform of basic education and motivation. But everything is not without foundation, the development of the starting point is based on "zero", especially the education reform, the historical accumulation and heritage is starting point and cornerstone of our progress. To this end, dialectical understanding and correctly handle the relationship between inheritance and innovation has become the key to the reform forward. A focal point of colleges and universities is to cultivate qualified technical personnel with the aim of teaching reform is to improve teaching quality and efficiency. The development of education technology to teaching reform has brought new opportunities and challenges [6-8]. 
To this end, we will focus on the listed aspects of the issues. On the teaching idea, pay attention to knowledge to paying attention to for this shift, from the simple teaching to comprehensive education, respect students' personality, concerned about the student's status, face up to the differences of the students and make them become the study master, the teaching method, in which the non-computer majors to heuristic, stimulate students' learning enthusiasm and initiative, to make them change from traditional learning to innovative learning. The teaching content and course system, in which the lags behind the times development to update the teaching contents, optimizing curriculum system, pay attention to solve the teaching content and the needs of society and era development problem of the separation. On the training mode, from the focus on knowledge accumulation to pay attention to the comprehensive ability training, from inheritance education to innovative education, the unification of the diversification of training mode to pay attention to cultivate students' personality transformation.

To guide students to pay attention to the transformation, that is, by the knowledge into ability and quality, the elements of talent includes three aspects: knowledge, ability and quality, be short of one cannot. Knowledge is not equal to ability and quality it must be transformed into ability and quality to reflect its value. Knowledge application must go through the training can be transformed into ability, must pass through internalization and environment influence, and to transform and the formation of the good quality. Improve the quality and enhance ability also need the required knowledge. There are outdated and forget the problems of knowledge with ability and quality is more stable for a long time.

\section{Conclusion}

In this paper, we conduct research on the development direction and trend of interior design education under the green building background. Constitute the application of art in interior design, not to look at in isolation, to fully combine aesthetic principles, materials, texture, light and other factors, because these factors directly affect the constitute form of the expression. We can't be here to constitute the application of art in interior design, only as a beginning, hope designers to change the understanding of traditional form of art, focus on the unique angle of view of form art to the "new look" in interior design which puts the design with a deeper meaning. Interior design education mode should conform to the requirement of the times development, gradually establish a system of the full range of open education, to cultivate students with noble moral accomplishment and spiritual realm, good cultural and artistic accomplishment, good study ability, creative ability, expression ability and competition ability. In the future, we will review more work for optimization of current research.

\section{References}

[1] Meggs, Susan Martin, Annette Greer, and Sharon Collins. "Virtual reality in interior design education: Enhanced outcomes through constructivist engagement in Second Life." International Journal of Web-Based Learning and Teaching Technologies (IJWLTT) 7.1 (2012): 19-35.

[2] Saw, S. H., et al. "A simple interactive 3D interior design application for living room." Frontiers of Communications, Networks and Applications (ICFCNA 2014-Malaysia), International Conference on. IET, 2014.

[3] Prinsloo, Ilse. "Embracing a culture of active citizenship in interior design education." The Design Education Forum of Southern Africa (www. defsa. org. za), 2013.

[4] Riera, Albert Sánchez, Ernest Redondo, and David Fonseca. "Lighting simulation in augmented reality scenes: Teaching experience in interior design." Information 
Systems and Technologies (CISTI), 2012 7th Iberian Conference on. IEEE, 2012.

[5] Smith, Kennon M. "Conditions influencing the development of design expertise: As identified in interior design student accounts." Design Studies 36 (2015): 77-98.

[6] Dickinson, Joan. "Annual Index of Interior Design Dissertations, Theses, and Creative Projects." Journal of Interior Design 38.3 (2013): 37-44.
[7] Tavşan, Filiz, and Elif Sönmez. "Interaction of Fashion and Interior Design Styles in Interior Architecture Education; Workshop Study." Procedia-Social and Behavioral Sciences 89 (2013): 687-691.

[8] Day, Julia, Judy Theodorson, and Kevin Van Den Wymelenberg. "Understanding controls, behaviors and satisfaction in the daylit perimeter office: a daylight design case study." Journal of Interior Design 37.1 (2012): 17-34. 